\title{
Fabrication and Evaluation of Matrix Type Novel Transdermal Patch Loaded with Tramadol Hydrochloride
}

\author{
(1) Shankhadip NANDI ${ }^{*}$, (1) Saptarshi MONDAL² \\ ${ }^{1}$ Eminent College of Pharmaceutical Technology, Department of Pharmaceutics, Kolkata, West Bengal, India \\ 2Bengal School of Technology, Department of Pharmaceutics, Chinsurah, West Bengal, India
}

\begin{abstract}
Objectives: Transdermal drug delivery as a novel drug delivery system has become a major research interest to the scientists for its controlled drug release and improved patient compliance. This study was conducted to develop an optimized transdermal patch of tramadol hydrochloride using an appropriate amount of suitable polymers. It was also planned to control the drug permeation rate from the device to achieve a sustained release pattern.

Materials and Methods: Several numbers of formulations were prepared by altering the amount of excipients. Physicochemical and biopharmaceutical parameters were checked to get the optimized formulation with desired characteristics.

Results: Fourier transform infrared spectroscopy results displayed no abnormal peaks and hence concluded that the drug and polymers were compatible with each other. The minimum standard deviation values of different physicochemical parameters assured that the method of preparation was skilled to develop patches with least intra-batch variability. A higher percentage of hydroxypropyl methylcellulose (HPMC) resulted in the greater tensile strength, moisture content and water vapor transmission rate of the patches. A high folding endurance value ( $>200)$ indicated the flexibility of the prepared patches and their integrity to the skin. The transdermal patches coded as F26 containing only HPMC polymer demonstrated the desired drug permeation rate (65.51\%) within 12 hours through ex vivo permeation studies.

Conclusion: The formulation coded as F26 was found to be the most optimized patch as it exhibited sustained drug permeation rate followed by higuchi diffusion kinetics, that also confirmed the capability of the formulation to exhibit matrix type drug delivery.
\end{abstract}

Key words: Optimized transdermal patch, tramadol hydrochloride, ex vivo permeation studies, higuchi diffusion kinetics, matrix type drug delivery

\section{INTRODUCTION}

In the recent few years, a research interest has been evolved to design a wide variety of novel drug delivery systems (NDDS) using the existing drug molecules.' Currently, transdermal drug delivery is considered as one of the most promising approaches for the implementation of NDDS. ${ }^{2}$ Topical dosage forms containing one or more therapeutic agents that can produce a systemic effect of the agent is termed as transdermal drug delivery system (TDDS). ${ }^{3}$ There are several advantages of TDDS like controlled release of the drug, steady blood-level profile, minimized systemic side effects, bypassing first-pass hepatic metabolism, self-administration, enhanced patient compliance, improved efficacy over any other conventional dosage forms.'
Transdermal system has been designed for delivering an effective amount of drug across the intact skin to accomplish both the local and systemic effects. ${ }^{4}$ Pain, hypertension, motion sickness, angina, nicotine addiction are the diseases which can be treated by the aid of transdermal delivery of drugs. Latest example of successfully using this system is healing of urinary incontinency and contraception. ${ }^{5}$ Transderm SCOP approved by Food and Drug Administration (FDA) in 1979, was the first transdermal system which was used to inhibit nausea and vomiting associated with motion sickness.' Creams, ointments, pastes, gels, lotions, sprays, and patches are the most common transdermal formulations available in the market. 
A transdermal patch is a user friendly, convenient and extensively accepted medicated adhesive device that distributes the drug through the skin for systemic effects in a controlled and programmed manner. ${ }^{6}$ Exposing of patch application site should be avoided from the external heat sources such as hot water bottles, hot water bags etc. A higher body temperature may also elevate the rate of drug release. Here, the patch must be removed immediately. Restricting nature of skin is one of a significant drawbacks for passive delivery of drugs through transdermal patches. ${ }^{7}$ Transdermal patches are classified into three types as the drug (i) in a reservoir system, (ii) in adhesive, (iii) in matrix.

The drug in matrix systems are developed by dispersing or dissolving the active pharmaceutical ingredient in a polymer matrix followed by adding an adhesive layer if desired. The polymer matrix regulates the rate of drug delivery. ${ }^{8,9}$ The selection of a polymer depends upon its physicochemical properties, compatibility with drug, optimization of the drug loaded into the matrix with other ingredients, skin contact, mode of drug release, and stability.10,11 Ideal drug candidates for transdermal patch that can readily permeate to the skin must have a low molecular weight, high therapeutic potency, be moderately lipophilic and being non-allergenic, and nonirritating. ${ }^{7}$ Tramadol hydrochloride is a 4-phenyl-piperidine analogue of the opioid drug codeine, 2-(dimethyl amino)methyl)-1-(3'-methoxyphenyl) cyclohexanol hydrochloride, which was first synthesized in $1962 .^{12}$ The drug is categorized as an analgesic and can be used to relieve from moderate to severe acute and chronic (cancer and non-cancer) pain, osteoarthritis. For treating dental pain, osteoarthritis flare pain, and chronic back pain, tramadol provides rapid onset and prolonged action along with acetaminophen. ${ }^{13}$ It has been evidenced that at small dosages, tramadol hydrochloride is an effective and safe treatment protocol for premature ejaculation, a common sexual disorder. ${ }^{14}$ The study out by Chandak and Verma ${ }^{15}$ indicated that the matrix type transdermal patches of tramadol fabricated with different grades and altered ratios of hydroxypropyl methylcellulose (HPMC) embraced adequate potential for transdermal delivery owing to controlled release pattern of drug from the patches and on the aegis of their in vitro and pharmacokinetic results. Recent experimental studies have demonstrated that the transdermal patch containing HPMC as a polymer in higher concentrations caused an increased drug release. ${ }^{16}$ This work focused on the development of an optimized sustained release transdermal patch of tramadol hydrochloride with suitable physicochemical properties and desired release kinetics.

\section{MATERIALS AND METHODS}

Tramadol hydrochloride was purchased from Emmennar Pharma Pvt. Ltd. (Visakhapatnam, India). Potassium dihydrogen orthophosphate, sodium hydroxide, triethyl citrate, HPMC E15, ethyl cellulose (EC), polyvinyl alcohol, potassium bromide, potassium chloride, polyethylene glycol (PEG) 400, n-octanol, calcium chloride (fused) were procured from Loba Chemie Pvt. Ltd. (Mumbai, India). HPMC E5 was provided by Colorcon Asia Pvt. Ltd. (Goa, India). Glycerol, propylene glycol, methanol was purchased from Merck Specialities Pvt. Ltd. (Mumbai, India). All these ingredients used were of analytical grade except $n$-octanol (high performance liquid chromatography grade) and potassium bromide [infrared (IR) spectroscopy grade].

\section{Identification of drugs}

Many monographic tests (Table 1) were employed as per $\operatorname{IP}^{17}$ to identify tramadol hydrochloride, which was used as the drug candidate for designing the formulations.

\section{Table 1. Specifications required for identification of drug ${ }^{17}$}

$\begin{array}{ll}\text { Tests } & \text { Specification }\end{array}$

Solubility

In water

In methanol

Freely soluble

In acetone

Freely soluble

Very slightly soluble

Appearance of solution

A $5.0 \%(w / v)$ solution of tramadol hydrochloride

Clear and colorless

\section{Acidity}

$0.2 \mathrm{~mL}$ of methyl red solution and $0.2 \mathrm{~mL}$ of $0.01 \mathrm{M}$ hydrochloric acid were added to $10 \mathrm{~mL}$ of $5.0 \%(\mathrm{w} / \mathrm{v})$

solution of tramadol hydrochloride

A specified amount of $0.01 \mathrm{M}$ sodium hydroxide was added to change the colour from red to yellow

Solution will be red

Loss on drying

$1.0 \mathrm{~g}$ tramadol hydrochloride was dried in a hot air oven at $105^{\circ} \mathrm{C}$ for $3 \mathrm{~h}$

Not more than $0.4 \mathrm{~mL}$

Sulfated ash

Not more than $0.5 \%$

Assay

$0.18 \mathrm{~g}$ of tramadol hydrochloride was dissolved in $25 \mathrm{~mL}$ of anhydrous acetic acid and $10 \mathrm{~mL}$ of

acetic anhydride. Then, it was then titrated with $0.1 \mathrm{M}$ perchloric acid. The end point was determined

potentiometrically. A blank titration was carried out $(1 \mathrm{~mL}$ of $0.1 \mathrm{M}$ perchloric acid is equivalent to $0.02998 \mathrm{~g}$ of

tramadol hydrochloride) 


\section{Compatibility of the drug with polymers}

Compatibility between the drug and polymers was examined using fourier transform IR spectroscopy (FT-IR) spectrophotometer. The IR spectra were recorded under a wave range between $4000-400 \mathrm{~cm}^{-1} .18,19$

\section{Preparation of backing membrane}

To prepare the backing membrane, $3 \mathrm{~g}$ of polyvinyl alcohol was dissolved in $100 \mathrm{~mL}$ of distilled water warmed at a temperature $40^{\circ} \mathrm{C}$. After filtering the solution, $2 \mathrm{~mL}$ filtrate was transferred to each glass mold. It was then placed in a tray dryer at $60^{\circ} \mathrm{C}$ for 6 hours to get dried. 20

\section{Formulation of matrix type transdermal patches}

A total 26 batches (F1-F26) of matrix type transdermal patches were fabricated using different ratios of HPMC and EC as a rate regulatory polymers (Table 2). PEG 400, glycerol, and triethyl citrate were used as plasticizers. Propylene glycol was added as an anti-crystalizing agent. The polymers and other excipients in different ratios (Table 2) were dissolved in methanol. Tramadol hydrochloride $(50 \mathrm{mg}$ ) was added slowly to the polymeric solutions of individual batch and stirred on a magnetic stirrer until a uniform mixture was obtained. The mixture was then poured on the glass mold, which was covered with a glass funnel of appropriate size to govern evaporation

Table 2. Composition of matrix type transdermal patches (F1-F26)

\begin{tabular}{|c|c|c|c|c|c|c|c|c|c|}
\hline \multirow[b]{2}{*}{ Patches } & \multicolumn{9}{|c|}{ Quantity/patch (mg) } \\
\hline & $\begin{array}{l}\text { Tramadol } \\
\mathrm{HCl}\end{array}$ & HPMC E5 & HPMC E15 & $\mathrm{EC}$ & PEG 400 & Glycerol & $\begin{array}{l}\text { Propylene } \\
\text { glycol }\end{array}$ & $\begin{array}{l}\text { Triethyl } \\
\text { citrate }\end{array}$ & $\begin{array}{l}\text { Total weight } \\
\text { (mg) }\end{array}$ \\
\hline $\mathrm{F} 1$ & 50 & - & - & 50 & 10 & - & - & 10 & 120 \\
\hline F2 & 50 & - & - & 100 & 10 & - & - & 10 & 170 \\
\hline F3 & 50 & - & - & 100 & 10 & 10 & - & - & 170 \\
\hline $\mathrm{F} 4$ & 50 & - & - & 100 & 20 & 10 & - & - & 180 \\
\hline F5 & 50 & - & - & 100 & 30 & 10 & - & - & 190 \\
\hline F6 & 50 & - & - & 100 & 20 & 20 & - & - & 190 \\
\hline F7 & 50 & - & - & 150 & 20 & 20 & - & - & 240 \\
\hline F8 & 50 & - & - & 200 & 20 & 20 & - & - & 290 \\
\hline F9 & 50 & 100 & - & - & 20 & 20 & - & - & 190 \\
\hline F10 & 50 & 150 & - & - & 20 & 20 & - & - & 240 \\
\hline F11 & 50 & 200 & - & - & 20 & 20 & - & - & 290 \\
\hline $\mathrm{F} 12$ & 50 & 100 & - & 100 & 20 & 20 & - & - & 290 \\
\hline $\mathrm{F} 13$ & 50 & 150 & - & 100 & 20 & 20 & - & - & 340 \\
\hline F14 & 50 & 200 & - & 100 & 20 & 20 & - & - & 390 \\
\hline F15 & 50 & 200 & 100 & - & 20 & 20 & - & - & 390 \\
\hline F16 & 50 & 200 & 200 & - & 20 & 20 & - & - & 490 \\
\hline F17 & 50 & 200 & 125 & - & 20 & 20 & - & - & 415 \\
\hline F18 & 50 & 200 & 125 & - & 20 & 20 & 10 & - & 425 \\
\hline F19 & 50 & 200 & 125 & - & 20 & 20 & 20 & - & 435 \\
\hline F20 & 50 & 200 & 125 & - & 20 & 20 & 15 & - & 430 \\
\hline F21 & 50 & 200 & 125 & - & - & 20 & 10 & - & 405 \\
\hline F22 & 50 & 200 & 125 & - & - & 30 & 10 & - & 415 \\
\hline F23 & 50 & 200 & 125 & - & - & 40 & 10 & - & 425 \\
\hline F24 & 50 & 200 & 125 & - & - & 50 & 10 & - & 435 \\
\hline F25 & 50 & 200 & 150 & - & - & 50 & 10 & - & 460 \\
\hline F26 & 50 & 250 & 190 & - & - & 50 & 10 & - & 550 \\
\hline
\end{tabular}

HPMC: Hydroxypropyl methylcellulose, EC: Ethyl cellulose, PEG: Polyethylene glycol 
rate of the solvent. The casting solvent was subsequently permitted to evaporate overnight at $40^{\circ} \mathrm{C}$ for attaining the dried patches. ${ }^{21}$ After drying, the patches were cut from the glass mold. Backing membrane was affixed with suitable adhesive and dried at the room temperature. The patches were then kept between sheets of wax paper and stored in desiccators for their evaluation followed by optimization. ${ }^{22,23}$

\section{Evaluation of matrix type transdermal patches}

Planned patches were evaluated for different physicochemical parameters such as thickness, drug content, moisture content, moisture uptake, flatness, tensile strength, water vapor transmission (WVT) rate, folding endurance, etc. $1,6,21$

\section{Thickness}

Thickness was measured using a digital screw gauge at five distinct portions of the patches from each batch and the mean value including standard deviation was calculated. ${ }^{24}$

\section{Weight variation}

Randomly selected ten patches from each batch were subjected to weight variation test. A specified area of the individual patch was cut into different parts and weighed. Average weight and standard deviation were calculated from the weights measured individually. ${ }^{25}$

\section{Drug content}

An accurately weighed $(100 \mathrm{mg}$ ) section of transdermal patch was dissolved in $100 \mathrm{~mL}$ of phosphate buffer $(\mathrm{pH} \mathrm{7.4)}$ and the solution was then shaken continuously for 24 hours in a shaker incubator followed by sonication for about $15 \mathrm{~min}$. After subsequent filtration and suitable dilution, the drug content in the solution was assessed using a ultraviolet (UV)-visible spectrophotometer at a wavelength of $275 \mathrm{~nm} \cdot{ }^{25,26}$

\section{Moisture content}

The patches from the individual batch were weighed individually and stored in a dessicator installed with activated silica at room temperature for 24 hours. The patches were then weighed repeatedly until a constant weight was found. Percentage moisture content was measured using the following formula. ${ }^{25,27}$

Percentage moisture content $=\frac{\text { Initial weight }- \text { Final weight }}{\text { Final weight }} \times 100$

\section{Moisture uptake}

A transdermal patch was weighed and placed in a dessicator containing a saturated solution of potassium chloride at room temperature for 24 hours. After the completion of the period, the patch was weighed repeatedly until a constant weight was found. Percentage moisture uptake was measured using the following formula. ${ }^{25}$

$$
\text { Percentage moisture uptake }=\frac{\text { Final weight }- \text { Initial weight }}{\text { Initial weight }} \times 100
$$

\section{Flatness}

A flatness test was performed to confirm that the developed patches retain a smooth surface and will not constrict with time. One longitudinal strip was cut from the center and two from either end of the patches which were individually measured. The variation in length caused by non-uniformity in flatness was checked by determining the percent constriction. Zero percent constriction is considered as equivalent to 100 percent flatness. Percentage constriction was calculated using the following formula. ${ }^{25,26}$

Percentage constriction $=\frac{\text { Initial length of strip }- \text { Final length of strip }}{\text { Initial length of strips }} \times 100$

\section{Folding endurance}

Folding endurance of the patches was estimated by repeatedly folding a small section of the patch $(2 \times 2 \mathrm{~cm})$ at the same place until it cracked. The number of times through which the patch could be folded at the same place without producing any crack line presented the folding endurance value. Three patches from each batch were considered for performing the test. ${ }^{28}$

\section{Tensile strength}

Transdermal patches were cut into $1 \mathrm{~cm}^{2}$ size and placed between two clamps of the tensilometer. Weight was gradually added so that the increasing pulling force could break the film. The force needed to break the patch was recognized as tensile strength expressed in the unit $\mathrm{kg} / \mathrm{cm}^{2} .{ }^{25}$

\section{Water vapor transmission rate}

The quantity of moisture transmitted through unit area of patch in unit time is expressed as the WVT rate. Glass vials of equal diameter and volume were used as transmission cells, which were washed thoroughly. After drying the vials in a hot air oven, about $1 \mathrm{~g}$ of anhydrous fused calcium chloride was taken in each vial, and the patch was affixed over the edge of the vial using a suitable sticking plaster. The weight of the vial was noted and kept in a desiccator comprising a saturated solution of potassium chloride for maintaining $84 \%$ relative humidity. These cells were removed from the desiccators after 24 hours and re-weighed. The water vapor transmission rate was determined as follows: ${ }^{28}$

Weight of water vapor transmitted $x$ Thickness of patch

WVT rate $=\frac{\text { Surface area exposed in square meters }}{\text { W }}$

\section{In vitro permeation studies}

Modified Franz diffusion cell was employed to conduct in vitro permeation studies. Mixed cellulose ester membrane was used as a dialysis (barrier) membrane which was previously soaked in distilled water for 24 hours. The transdermal patches were adhered to the dialysis membrane and the membrane was tied firmly to the donor compartment of the diffusion cell. The receptor compartment of the diffusion cell was filled with $85 \mathrm{~mL}$ of phosphate buffer $(\mathrm{pH}$ 7.4). The donor compartment 
was lowered to the receptor compartment in such a way that the dialysis membrane only touched the media of the receptor compartment. This assembly was constructed on a magnetic stirrer with a heater. Temperature of the receptor compartment was maintained at $37 \pm 2^{\circ} \mathrm{C}$. The content of the diffusion cell was continuously stirred using a teflon-coated bead at a constant speed of $600 \mathrm{rpm}$. Samples were taken at specified intervals of time and the same amount of phosphate buffer $(\mathrm{pH} \mathrm{7.4)}$ was added to maintain the sink condition. After suitable dilution, the samples were examined for percent drug content using UVvisible spectrophotometer at a wavelength of $275 \mathrm{~nm} .{ }^{21}$ In vitro permeation study was conducted for 6 hours..$^{29,30}$

\section{Ex vivo skin permeation studies}

In ex vivo skin permeation studies, goat skin was used as a dialysis (barrier) membrane which was obtained from a local slaughterhouse. The skin was thoroughly cleaned with running tap water followed by eliminating full thickness and non-dermatome skin using a scalpel. ${ }^{31}$ It was then soaked in an isotonic solution for $30 \mathrm{~min}$. Ex vivo permeation study was conducted for 12 hours. Procedure mentioned for in vitro permeation studies was followed for performing these studies. ${ }^{32}$

\section{Drug release kinetics study}

Data obtained from in vitro and ex vivo permeation studies were fitted to different mathematical models such as zero order, first order, and Higuchi release kinetics to define the kinetics and pattern of drug release. ${ }^{33}$ Statistical analysis was not used in this study.

\section{RESULTS AND DISCUSSION}

\section{Identification of drugs}

Several monographic tests were performed (Table 3) to check the identity of tramadol hydrochloride. Obtained results matched satisfactorily with their corresponding specification required. ${ }^{17}$ Hence, monographic tests confirmed the identity of tramadol hydrochloride.

\section{Fourier transform infrared spectroscopy}

The drug and polymeric materials were found to be physically compatible with each other. The characteristic absorption peak obtained from FT-IR spectra of tramadol hydrochloride (Figure 1) resembled almost the same with the spectra of standard sample of that. It was evidently manifest that the individual characteristics bands of tramadol hydrochloride (Figure 1), and the polymers HPMC E5 (Figure 2), HPMC E15 (Figure 3), EC (Figure 4) at the particular wavenumbers were also present in the FT-IR spectra analyzed for the physical mixtures of the drug along with these polymers (Figure 5, Table 4). Interpretation from the FT-IR studies directed that the drug was pure and chemically compatible with the polymers used. HPMC, as a hydrophilic polymer and EC, as a water insoluble polymer were used in the formulations.

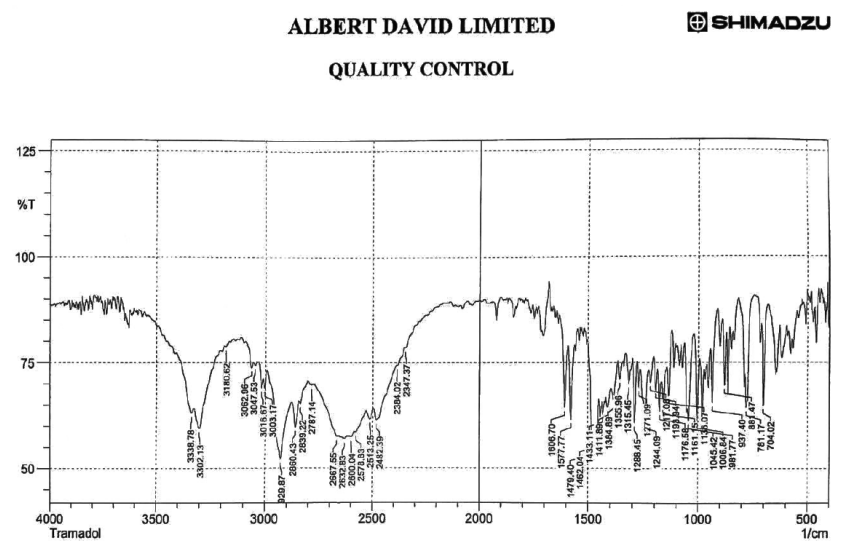

Figure 1. FT-IR spectra of tramadol hydrochloride FT-IR: Fourier transform infrared spectroscopy

Table 3. Identification of drug by performing several monographic tests

\section{Tests}

Solubility

In water

In methanol

In acetone
Obtained result

Freely soluble

Freely soluble

Very slightly soluble

Appearance of solution

A $5.0 \%(\mathrm{w} / \mathrm{v})$ solution of tramadol hydrochloride

Clear and colorless

Acidity

$0.2 \mathrm{~mL}$ of methyl red solution and $0.2 \mathrm{~mL}$ of $0.01 \mathrm{M}$ hydrochloric acid were added to $10 \mathrm{~mL}$ of

$5.0 \%(\mathrm{w} / \mathrm{v})$ solution of tramadol hydrochloride

A specified amount of $0.01 \mathrm{M}$ sodium hydroxide is added to change the colour from red to yellow A yellow color appeared after adding $0.3 \mathrm{~mL}$

Loss on drying

$1.0 \mathrm{~g}$ Tramadol hydrochloride was dried in a hot air oven at $105^{\circ} \mathrm{C}$ for $3 \mathrm{~h}$

$0.3 \%$

Sulfated ash

$0.087 \%$

\section{Assay}

$0.18 \mathrm{~g}$ of tramadol hydrochloride was dissolved in $25 \mathrm{~mL}$ of anhydrous acetic acid and $10 \mathrm{~mL}$ of

acetic anhydride. Then, it was titrated with $0.1 \mathrm{M}$ perchloric acid. The end point is determined

potentiometrically. A blank titration was then carried out $(1 \mathrm{~mL}$ of $0.1 \mathrm{M}$ perchloric acid is 


\section{ALBERT DAVID LIMITED QUALITY CONTROL}

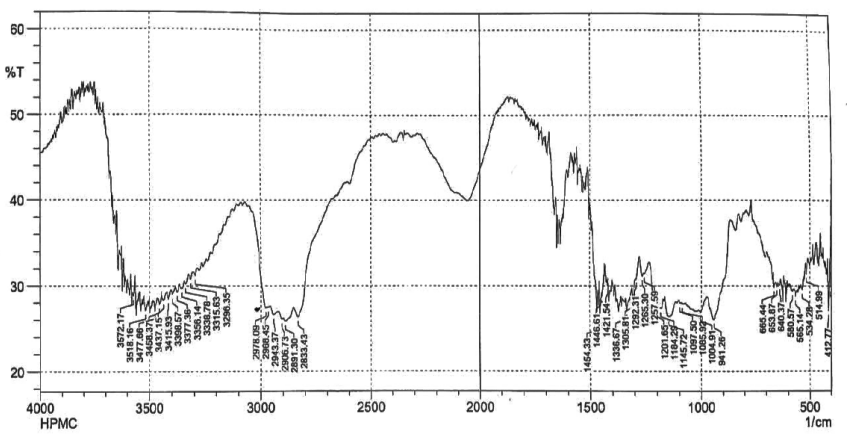

Figure 2. FT-IR spectra of HPMC E5

HPMC: Hydroxypropyl methylcellulose, FT-IR: Fourier transform infrared spectroscopy

円SHIMADZU
ALBERT DAVID LIMITED

ФSHIMADZU QUALITY CONTROL

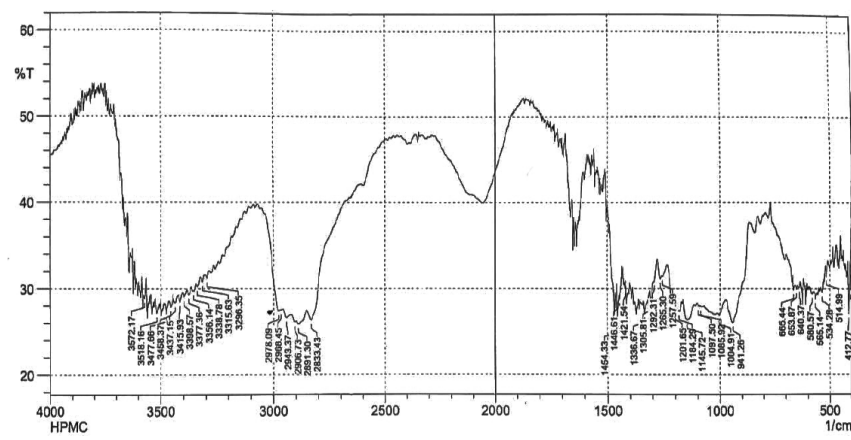

Figure 3. FT-IR spectra of HPMC E15

HPMC: Hydroxypropyl methylcellulose, FT-IR: Fourier transform infrared spectroscopy
ALBERT DAVID LIMITED QUALITY CONTROL

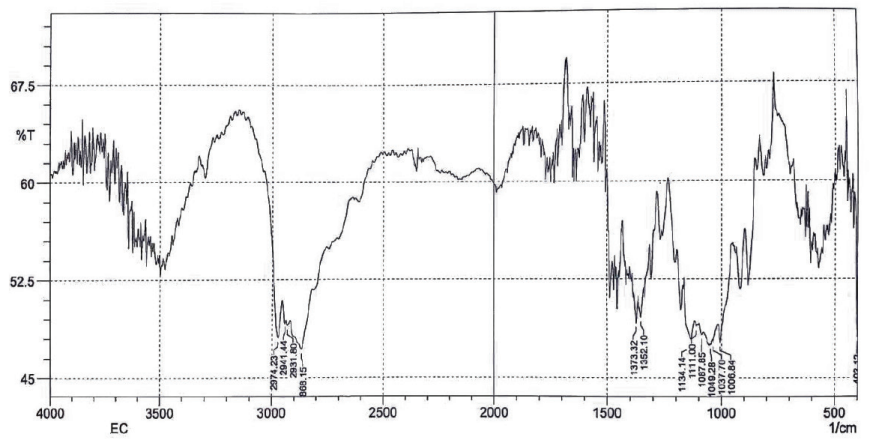

Figure 4. FT-IR spectra of EC

FT-IR: Fourier transform infrared spectroscopy, EC: Ethyl cellulose

ALBERT DAVID LIMITED

円SHIMADZU QUALITY CONTROL

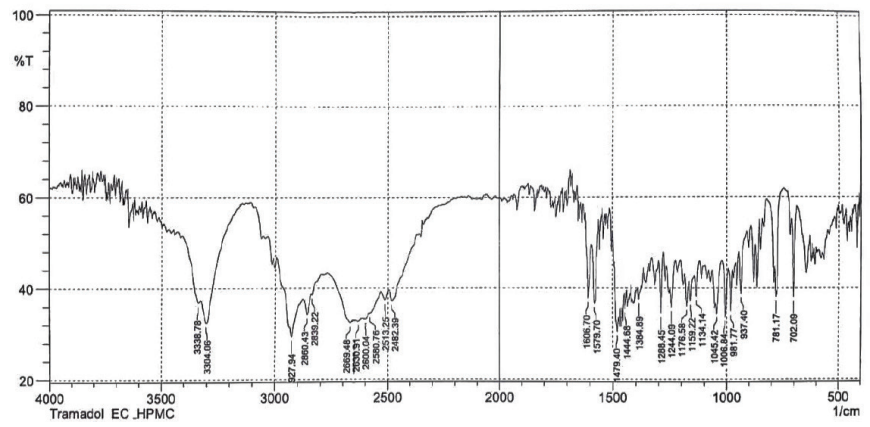

Figure 5. FT-IR spectra of tramadol hydrochloride along with polymers used

FT-IR: Fourier transform infrared spectroscopy

\section{Table 4. Interpretation of FT-IR spectrum}

\begin{tabular}{|c|c|c|c|c|c|}
\hline $\begin{array}{l}\text { Wave number of tramadol } \\
\text { hydrochloride }\left(\mathrm{cm}^{-1}\right)\end{array}$ & $\begin{array}{l}\text { Wave number of } \\
\text { HPMC E5 }\left(\mathrm{cm}^{-1}\right)\end{array}$ & $\begin{array}{l}\text { Wave number of } \\
\text { HPMC E15 }\left(\mathrm{cm}^{-1}\right)\end{array}$ & $\begin{array}{l}\text { Wave number } \\
\text { of } E C\left(\mathrm{~cm}^{-1}\right)\end{array}$ & $\begin{array}{l}\text { Wave number of drugs } \\
\text { along with polymers }\left(\mathrm{cm}^{-1}\right)\end{array}$ & Interpretation \\
\hline 3047.53 & 3077.60 & 3079.41 & 3080.51 & 3081.61 & $\mathrm{C}-\mathrm{H}$ stretching (aromatic) \\
\hline 1479.40 & 1478.10 & 1479.08 & 1479.38 & 1479.40 & $-\mathrm{CH}_{3}$ bending \\
\hline 2839.22 & 2833.43 & 2833.91 & 2838.82 & 2839.22 & $\mathrm{C}-\mathrm{H}$ stretching \\
\hline 1240.51 & 1241.02 & 1240.43 & 1241.53 & 1240.58 & C-O stretching \\
\hline
\end{tabular}

FT-IR: Fourier transform infrared spectroscopy, HPMC: Hydroxypropyl methylcellulose, EC: Ethyl cellulose

\section{Evaluation of matrix type transdermal patches}

Based on the observations found from the physical appearance of all batches (F1-F26) of transdermal patches (Table 5), only eleven batches were nominated for evaluation.
Physicochemical parameters

Thickness of the patches ranged from 0.47 to $0.57 \mathrm{~mm}( \pm 0.003$ to \pm 0.007 ) while the average weight of the patches varied from 289.89 to $558.16 \mathrm{mg}$ ( \pm 0.40 to \pm 0.48 ) (Table 6 ). These minimum SD values assured that the method of preparation was skilled to develop patches with least intrabatch variability. Satisfactory 
percentage of drug content with minimum SD value (Table 6) was found throughout all patches. Table 6 displays that increased amounts of HPMC caused an increase in the percentage of moisture content and moisture uptake of the transdermal patches due to hydrophilic properties of HPMC. Patel et al. ${ }^{23}$ reported that a higher percentage of HPMCs results in a higher moisture content. However, lower percentage of moisture content of the batches was capable of prevent the patches from microbial contamination and retarding their bulkiness. Flatness of the transdermal patches shown in Table 6 indicated a minimum level constriction just close to zero percent. Folding endurance value was found to be greater than 200 in all batches with minimum SD value $( \pm 0.51$ to \pm 0.58 ) (Table 7 ) which proved that the prepared transdermal patches were flexible enough, able to withstand mechanical pressure and proficient to retain the integrity with skin folding after its application. From Tables 6 and 7, it was reported that decreasing in the thickness of the patches accomplished a higher folding endurance value. The patches containing higher amounts of HPMC showed greater tensile strength, whereas an increasing amount of EC lowered the strength. Limpongsa and Umprayn ${ }^{34}$ also reported that the addition of EC resulted in the lower tensile strength. Due to the hydrophilic properties of HPMC, the films containing a higher proportion of HPMC showed greater WVT rate and addition of EC lowered it.

\section{In vitro and ex vitro permeation studies}

Because of their long-term release pattern, only F14, F18, F23, and F26 batches were selected (Table 8) for ex vivo skin permeation and kinetics study. The results obtained from in vitro permeation studies showed controlled drug release as the concentration of EC decreased. The formulation F26 containing the higher amounts of HPMC E5, HPMC E15 as polymers

\section{Table 5. Physical appearance of the planned transdermal patches (F1-F26)}

\begin{tabular}{|c|c|c|}
\hline Formulation code & Observation & Remarks \\
\hline F1 & Patch was not formed & Rejected \\
\hline F2 & Patch was formed, but became brittle on drying & Rejected \\
\hline F3 & Patch was brittle; crystallization occurred on drying & Rejected \\
\hline F4 & Patch was not formed & Rejected \\
\hline F5 & Showed crystallization and enhanced brittleness & Rejected \\
\hline F6 & Crystallization has occurred & Rejected \\
\hline F7 & Patch was formed firmly & Selected \\
\hline F8 & Patch was formed firmly & Selected \\
\hline F9 & Patch was not formed & Rejected \\
\hline F10 & Patch was formed, but crystallization occurred & Rejected \\
\hline F11 & Better than F10, crystallization occurred in negligible amounts & Selected \\
\hline $\mathrm{F} 12$ & Better than F10, crystallization occurred in negligible amounts & Selected \\
\hline F13 & Patch was not formed & Rejected \\
\hline F14 & Better than F11 and F12 & Selected \\
\hline F15 & Patch was formed firmly & Selected \\
\hline F16 & Patch was formed, but enhanced crystallization was found & Rejected \\
\hline $\mathrm{F} 17$ & Patch was formed, but slightly brittle & Rejected \\
\hline F18 & Patch was formed firmly & Selected \\
\hline F19 & Patch was sticky & Rejected \\
\hline $\mathrm{F} 20$ & Patch was sticky & Rejected \\
\hline F21 & Patch was more brittle than F17 & Rejected \\
\hline $\mathrm{F} 22$ & Patch was more brittle than F17 & Rejected \\
\hline F23 & Patch was formed firmly & Selected \\
\hline F24 & Patch was formed firmly & Selected \\
\hline F25 & Better patch from all respects & Selected \\
\hline F26 & Better patch from all respects & Selected \\
\hline
\end{tabular}


Table 6. Evaluation of physicochemical parameters of the selected transdermal patches

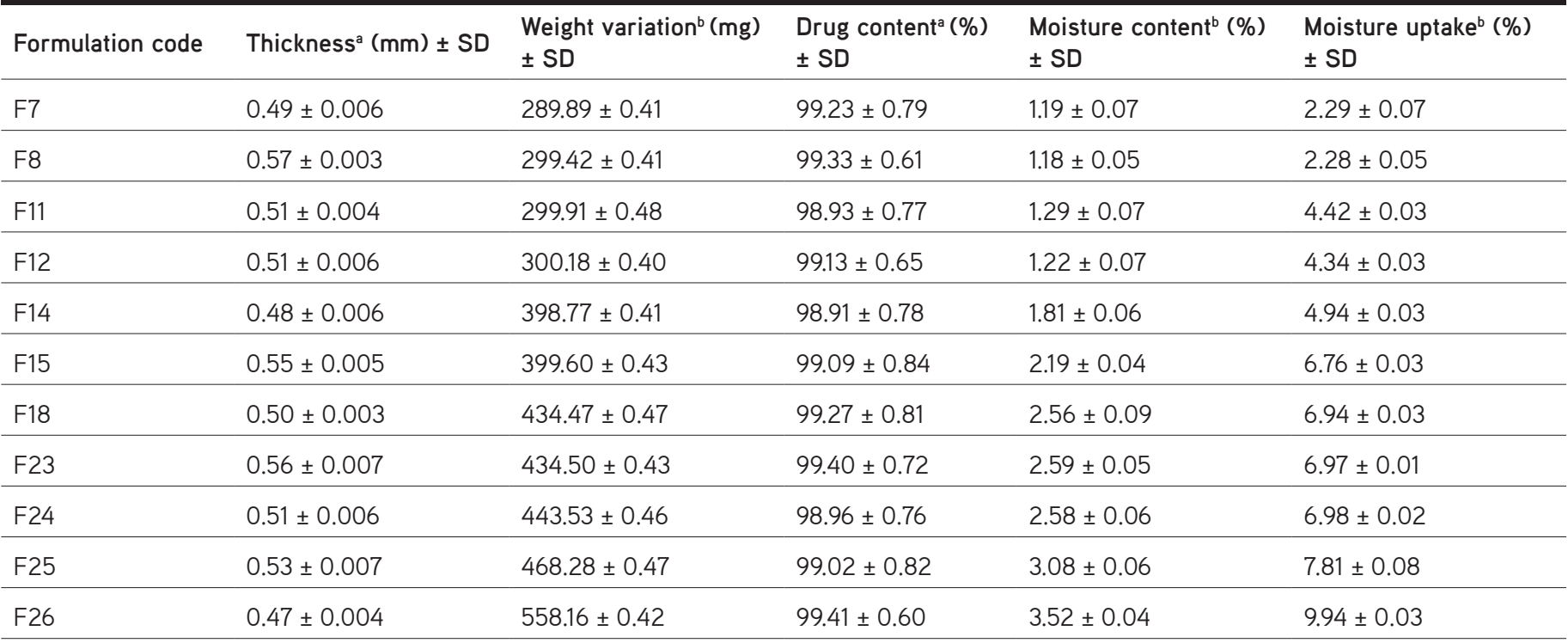

All values are expressed as mean SD, a ${ }^{\mathrm{n}}: 10,{ }^{b} \mathrm{n}: 5, \mathrm{SD}$ : Standard deviation

Table 7. Evaluation of physicochemical parameters of selected transdermal patches

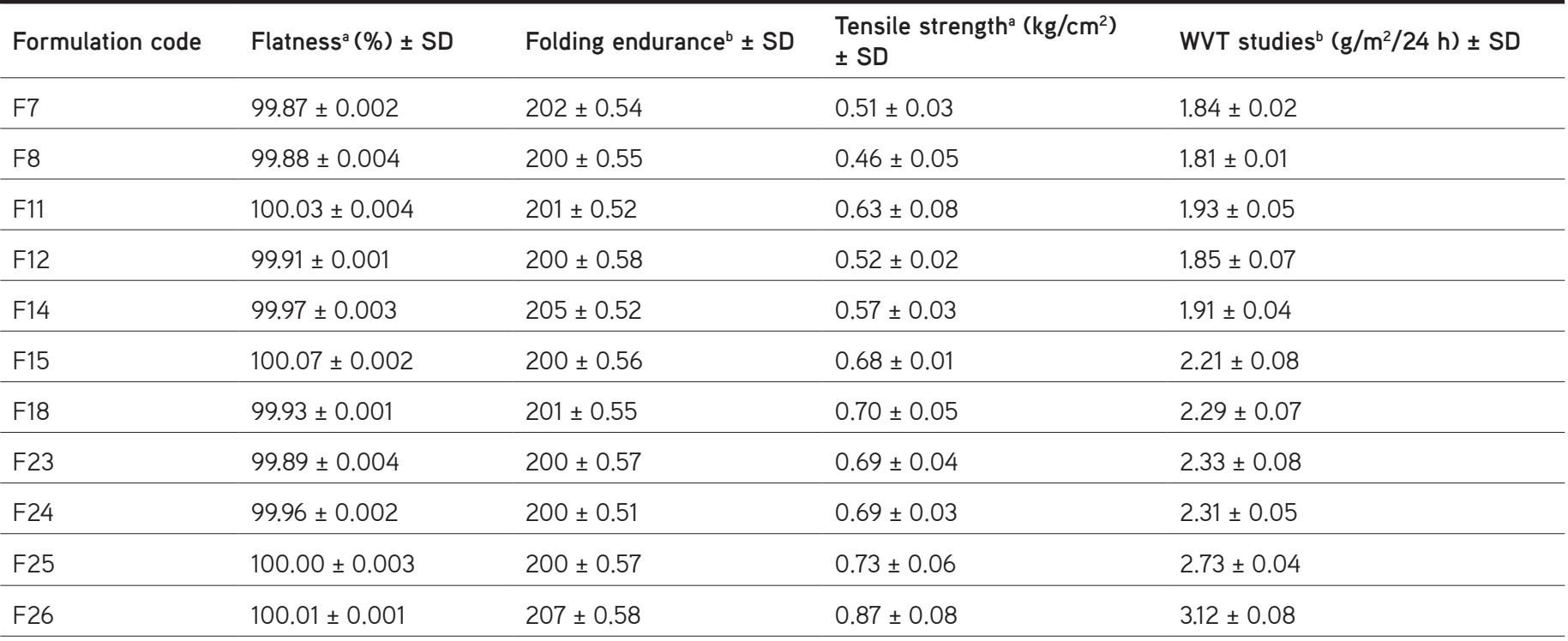

All values are expressed as mean SD, an: 10, ${ }^{b} \mathrm{n}: 5, \mathrm{SD}$ : Standard deviation, WVT: Water vapor transmission

Table 8. In vitro permeation study of matrix type transdermal patches

\begin{tabular}{|c|c|c|c|c|c|c|c|c|c|c|c|}
\hline \multirow{2}{*}{ Time (min) } & \multicolumn{11}{|c|}{ Percentage cumulative drug release } \\
\hline & $\mathrm{F} 7$ & F8 & $\mathrm{F} 11$ & $\mathrm{~F} 12$ & $\mathrm{~F} 14$ & F15 & F18 & F23 & $\mathrm{F} 24$ & $\mathrm{~F} 25$ & F26 \\
\hline 0 & 0 & 0 & 0 & 0 & 0 & 0 & 0 & 0 & 0 & 0 & 0 \\
\hline 30 & 49.51 & 26.74 & 49.76 & 31.46 & 27.22 & 36.62 & 29.68 & 34.57 & 40.21 & 32.36 & 21.46 \\
\hline 60 & 85.43 & 41.87 & 91.48 & 68.63 & 38.64 & 51.62 & 40.12 & 42.55 & 48.19 & 45.62 & 30.26 \\
\hline 120 & 98.52 & 69.49 & 90.13 & 88.67 & 52.58 & 68.32 & 54.54 & 61.31 & 66.95 & 62.74 & 42.10 \\
\hline 240 & 97.78 & 86.31 & - & 87.31 & 69.83 & 87.82 & 72.46 & 80.35 & 83.56 & 85.12 & 60.28 \\
\hline 360 & - & 93.78 & - & - & 78.24 & 101.87 & 83.22 & 88.77 & 94.41 & 99.63 & 71.96 \\
\hline
\end{tabular}


showed a rate regulatory drug-release pattern compared to the other formulations. As a plasticizer, effect of glycerol was most satisfactory with increased concentration of HPMC in the formulation F26, which showed the controlled in vitro drug release.

The effect of polymers and plasticizers on the results of ex vivo permeation studies was the same as the ingredients that influenced the results of in vitro permeation studies. Percentage cumulative drug release from the formulations was found to be more than $60 \%$ after 12 hours (Table 9 ), which was considered satisfactory. In vitro (Table 8 ) and ex vivo drug release profiles (Table 9) of the mentioned batches were fitted into different

\section{Table 9. Ex vivo permeation study of matrix type transdermal} patches

\begin{tabular}{lllll}
\multirow{2}{*}{ Time $(\mathrm{min})$} & \multicolumn{4}{l}{ Percentage cumulative drug release } \\
\cline { 2 - 5 } & F14 & F18 & F23 & F26 \\
\hline 0 & 0 & 0 & 0 & 0 \\
\hline 30 & 11.15 & 15.87 & 19.67 & 12.78 \\
\hline 60 & 20.88 & 24.83 & 28.56 & 18.42 \\
\hline 120 & 34.82 & 35.78 & 45.71 & 29.25 \\
\hline 240 & 52.07 & 52.776 & 58.51 & 42.17 \\
\hline 360 & 60.48 & 63.98 & 69.87 & 50.11 \\
\hline 480 & 68.61 & 72.66 & 80.78 & 57.26 \\
\hline 720 & 71.98 & 75.87 & 83.71 & 65.51 \\
\hline
\end{tabular}

kinetic models (Figures 6 and 7). The data obtained from Table 10 explained that the selected batches except F23 were best fitted to Higuchi release kinetics for in vitro permeation studies. The rate of permeation of the drug through goat skin was slower and in a sustained manner compared to in vitro release profile. This could be explained by comparing the thickness of the goat skin membrane with that of dialysis membrane used. However, the data obtained from Table 11 clarified that the selected batches were best fitted to Higuchi release kinetics for ex vivo permeation studies.

\section{Table 10. Values of correlation coefficient of different kinetics} models for in vitro permeation study

\begin{tabular}{lllll}
\multirow{2}{*}{$\begin{array}{l}\text { Release } \\
\text { kinetics }\end{array}$} & \multicolumn{4}{l}{ Correlation coefficients $\left(\mathrm{R}^{2}\right)$} \\
\cline { 2 - 5 } & F14 & F18 & F23 & F26 \\
\hline Zero order & 0.840 & 0.849 & 0.827 & 0.905 \\
\hline First order & 0.964 & 0.980 & 0.984 & 0.983 \\
\hline Higuchi & 0.986 & 0.990 & 0.981 & 0.999 \\
\hline
\end{tabular}

Table 11. Values of the correlation coefficient of different kinetics model for ex vivo permeation study

\begin{tabular}{lllll}
\hline \multirow{2}{*}{ Release kinetics } & \multicolumn{4}{l}{ Correlation coefficients $\left(R^{2}\right)$} \\
\cline { 2 - 5 } & F14 & F18 & F23 & F26 \\
\hline Zero order & 0.837 & 0.845 & 0.825 & 0.887 \\
\hline First order & 0.924 & 0.937 & 0.947 & 0.961 \\
\hline Higuchi & 0.969 & 0.978 & 0.973 & 0.993 \\
\hline
\end{tabular}
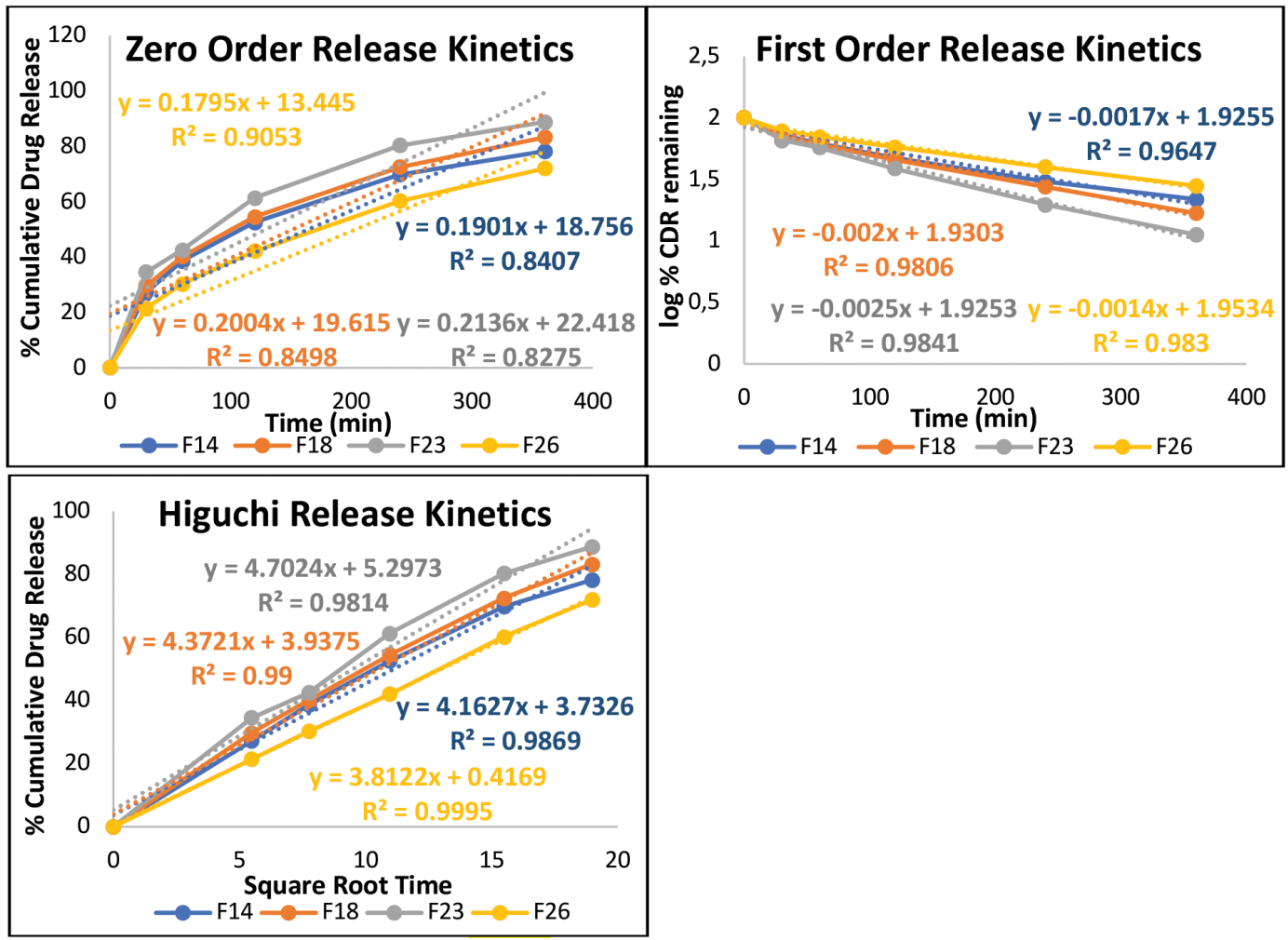

Figure 6. Fitting the data obtained from in vitro permeation study to a different kinetics model 


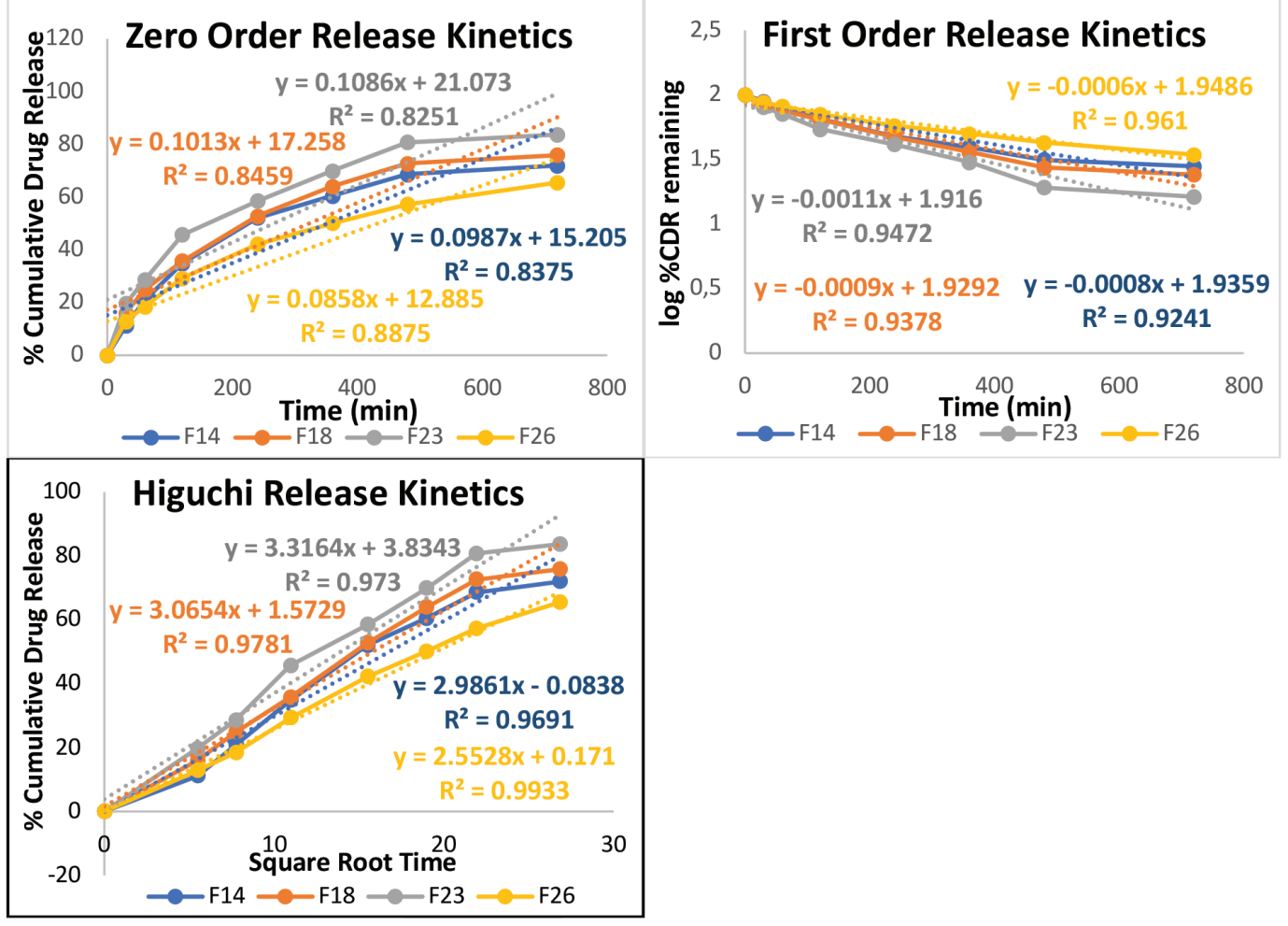

Figure 7. Fitting the data obtained from ex vivo permeation study to a different kinetics model

Depending upon the results obtained from physicochemical evaluations performed and particularly based on the sustained release profile, F26 was designated as the optimized formulation. For this formulation, the best kinetics model was the Higuchi equation, whereas the plots exposed great linearity with highest $R^{2}$ values (Figures 6 and 7 ), suggesting the process of diffusion. Hence, it was confirmed that the formulation was capable of exhibiting matrix type drug delivery.

\section{CONCLUSION}

To achieve better bioavailability and improved patient compliance, optimized matrix type novel transdermal patches containing tramadol hydrochloride were developed with higher amounts of HPMC as rate regulating polymer. As per ex vivo drug release, the concern was that the optimized formulation permeated only $65.51 \%$ drug through goat skin within 12 hours (Table 9). This indicated a window for using a permeation enhancer in the formulation to improve the drug permeation rate through the goat skin. However, further ex vivo permeation studies must be conducted to determine the suitable permeation enhancer.

\section{ACKNOWLEDGEMENTS}

The authors acknowledge their gratitude to the management of Albert David Limited, Kolkata, West Bengal, for providing their R\&D laboratory facility to conduct the necessary research work. Authors would also like to thank Mr. Souvik Ghatak, Senior Chemist, R\&D Department, Albert David Limited, Kolkata for his esteemed guidance to complete this research work.
Ethics

Ethics Committee Approval: Not applicable.

Informed Consent: Not applicable.

Peer-review: Externally peer-reviewed.

\section{Authorship Contributions}

Surgical and Medical Practices: S.M., Concept: S.M., Design: S.N., S.M., Data Collection or Processing: S.N., S.M., Analysis or Interpretation: S.N., S.M., Literature Search: S.N., Writing: S.N.

Conflict of Interest: No conflict of interest was declared by the authors.

Financial Disclosure: The authors declared that this study received no financial support.

\section{REFERENCES}

1. Tanwar H, Sachdeva R. Transdermal drug delivery system: a review. Int J Pharm Sci Res. 2016;7:2274-2290.

2. Rani S, Saroha K, Syan N, Mathur P. Transdermal patches a successful tool in transdermal drug delivery system: an overview. Der Pharmacia Sinica. 2011;2:17-29.

3. Zaman M, Khalid U, Raja MAG, Siddique W, Sultana K, Amjad MW, Ur Rehman A, Khan MA. Fabrication and characterization of matrix type transdermal patches loaded with ramipril and repaglinide via cellulose based hydrophilic and hydrophobic polymers: in-vitro and ex-vivo permeation studies. Polymer-Plastics Technology and Engineering. 2017;56:1713-1722.

4. Alexander A, Dwivedi S, Ajazuddin, Giri TK, Saraf S, Saraf S, Tripathi DK. Approaches for breaking the barriers of drug permeation through transdermal drug delivery. J Control Release. 2012;164:26-40. 
5. Thomas BJ, Finnin BC. The transdermal revolution. Drug Discov Today. 2004;9:697-703.

6. Nair RS, Ling TN, Shukkoor MSA, Manickam B. Matrix type transdermal patches of captopril: ex vivo permeation studies through excised rat skin. J Pharm Res. 2013;6:774-779.

7. Suksaeree J, Thuengernthong A, Pongpichayasiri K, Maneewattanapinyo P, Settharaksa S, Pichayakorn W. Formulation and evaluation of matrix type transdermal patch containing silver nanoparticles. J Polym Environ. 2018;26:4369-4375.

8. Pichayakorn W, Suksaeree J, Boonme P, Amnuaikit T, Taweepreda W, Ritthidej GC. Deproteinized natural rubber latex/hydroxypropylmethyl cellulose blending polymers for nicotine matrix films. Ind Eng Chem Res. 2012;51:8442-8452.

9. Wokovich AM, Prodduturi S, Doub WH, Hussain AS, Buhse LF. Transdermal drug delivery system (TDDS) adhesion as a critical safety, efficacy and quality attribute. Eur J Pharm Biopharm. 2006;64:1-8.

10. Sugibayashi K, Morimoto Y. Polymers for transdermal drug delivery systems. J Control Release. 1994:29:177-185.

11. Valenta C, Auner BG. The use of polymers for dermal and transdermal delivery. Eur J Pharm Biopharm. 2004;58:279-289.

12. Subedi M, Bajaj S, Kumar MS, Yc M. An overview of tramadol and its usage in pain management and future perspective. Biomed Pharmacother. 2019;111:443-451.

13. Dhillon S. Tramadol/paracetamol fixed-dose combination: a review of its use in the management of moderate to severe pain. Clin Drug Investig. 2010;30:711-738. Erratum in: Clin Drug Investig. 2010;30:866.

14. Eassa BI, El-Shazly MA. Safety and efficacy of tramadol hydrochloride on treatment of premature ejaculation. Asian J Androl. 2013;15:138-142.

15. Chandak AR, Verma PRP. Development and evaluation of HPMC based matrices for transdermal patches of tramadol. Clin Res Regul Aff. 2008;25:13-30.

16. Garala KC, Garala RJ, More HN, Shinde AJ. Effect of cross-linking agent on the release of drug from the transdermal matrix patches of tramadol hydrochloride. Res J Pharm and Tech. 2008;1:187-192.

17. Government of India, Ministry of Health \& Family Welfare. Indian Pharmacopoeia. The Indian Pharmacopoeia Commission, Ghaziabad. $6^{\text {th }}$ ed. 2010. Ghaziabad, India.

18. Amrutkar JR, Gattani SG. Chitosan-chondroitin sulfate based matrix tablets for colon specific delivery of indomethacin. AAPS PharmSciTech. 2009;10:670-677.

19. Biswas GR, Chakraborty S, Das U, Majee SB. Insight into the release kinetics of amoxicillin trihydrate from buccoadhesive tablets with a natural gum. Res J Pharm Biol Chem. 2014;5:772-785.

20. Asija R. Gupta A, Maheshwari BS. Formulation and evaluation of transdermal patches of torasemide. Int J Adv Sci. 2015;1:38-44.
21. Shinde AJ, Garala KC, More HN. Development and characterization of transdermal therapeutics system of tramadol hydrochloride. Asian $\mathrm{J}$ Pharm Sci. 2008;2:265-269.

22. Wahid A, Sridhar BK, Shivakumar S. Preparation and evaluation of transdermal drug delivery system of etoricoxib using modified chitosan. Indian J Pharm Sci. 2008;70:455-460.

23. Patel MN, Bharadia PD, Patel MM. Formulation \& evaluation of matrix type transdermal patches based on composite polymers. Int J Pharm Res. 2012;4:53-58.

24. Palanisamy P, Jaykar B, Venkateswarlu BS, Chandira RM, Suriyan D. A review on transdermal drug delivery system. Indian $\mathrm{J}$ Nat Sci. 2020;10:27035-27056.

25. Sachan R, Bajpai M. Transdermal drug delivery system: a review. Int J Res Dev Pharm Life Sci. 2013;3:748-765.

26. Parivesh S, Sumeet D, Abhishek D. Design, evaluation, parameters and marketed products of transdermal patches: a review. J Pharma Res. 2010;3:235-240.

27. Gannu R, Vishnu YV, Kishan V, Rao YM. Development of nitrendipine transdermal patches: in vitro and ex vivo characterization. Curr Drug Deliv. 2007;4:69-76.

28. Singh A, Bali A. Formulation and characterization of transdermal patches for controlled delivery of duloxetine hydrochloride. J Anal Sci Technol. 2016;7:25.

29. Ng SF, Rouse JJ, Sanderson FD, Meidan V, Eccleston GM. Validation of a static Franz diffusion cell system for in vitro permeation studies. AAPS PharmSciTech. 2010;11:1432-1441.

30. Salamanca CH, Barrera-Ocampo A, Lasso JC, Camacho N, Yarce CJ. Franz Diffusion cell approach for pre-formulation characterisation of ketoprofen semi-solid dosage forms. Pharmaceutics. 2018;10:148.

31. Gupta V, Trivedi P. Ex vivo localization and permeation of cisplatin from novel topical formulations through excised pig, goat, and mice skin and in vitro characterization for effective management of skin-cited malignancies. Artif Cells Nanomed Biotechnol. 2015;43:373-382.

32. Marwah H, Garg T, Rath G, Goyal AK. Development of transferosomal gel for trans-dermal delivery of insulin using iodine complex. Drug Deliv. 2016;23:1636-1644.

33. Nandi S, Deb P, Banerjee J, Reza KH. Formulation and evaluation of enteric coated elementary osmotic pump (ECEOP) tablets of diclofenac sodium. Int J Pharm Sci Res. 2020;11:5703-5711.

34. Limpongsa E, Umprayn K. Preparation and evaluation of diltiazem hydrochloride diffusion-controlled transdermal delivery system. AAPS PharmSciTech. 2008;9:464-470. 